\title{
An Evaluation of Chemicals for the Toxicity to Brown Snail (Helix aspersa Müller) on Grapevines*
}

\author{
A. Schwartz ${ }^{1}$ and D. Capatos ${ }^{2}$ \\ 1) Viticultural and Oenological Research Institute (VORI), Private Bag X5026, 7600 Stellenbosch, Republic of South Africa. \\ 2) Biometric Services, Winter Rainfall Region, Private Bag, 7607 Elsenburg, Republic of South Africa. \\ Submitted for publication: January 1990 \\ Accepted for publication: May 1990 \\ Keywords: Helix aspersa, snails, toxicity, grapevine
}

\begin{abstract}
A field trial was carried out to evaluate chemicals for toxicity to Helix aspersa Müller on vines. The comparison of treatments was complicated by major inequalities of snail counts. A weighted logistic regression method was, therefore, employed to identify significant differences among treatments. The highest percentage kill was obtained with metaldehyde applied as a paste onto each vine cordon. Copper sulphate spray at $5 \%$ and $10 \%$ strength gave comparable kill rates but was phytotoxic to the vegetative parts of the vine and consequently should be further evaluated as treatments restricted to the trunk of the vine only. Alphamethrin, azinphos-methyl and metaldehyde were unsatisfactory as sprays.
\end{abstract}

The brown snail, Helix aspersa Müller, has been a pest of grapevines for many years. The current method of control is by means of granular toxic baits, which are applied to the soil surface close to the vine trunk. This approach is tedious, expensive and not completely reliable. Since no chemicals are registered that can be applied directly to the vine for the control of snails it was considered necessary to evaluate appropriate chemicals as arboreal applications in a field trial.

The snail-inhibiting characteristics of copper sulphate are well known (Godan, 1983). Loubser (1982) used a combination of lime and copper sulphate dust on vines infested with Theba pisana (Müller), but without much success. Azinphosmethyl has been recommended as a spray against both $H$. aspersa and T. pisana in Australia (Anon., 1977). Alphamethrin is one of the pyrethroids generally used for the control of snoutbeetles at a time when H. aspersa is active; therefore the possibility of simultaneous control exists. An emulsifiable concentrate of metaldehyde is recommended as a spray on garden shrubs but has not previously been tested on vines. All these chemical sprays were therefore included in a vineyard experiment, together with a viscous, non-sprayable metaldehyde bait in the form of a paste which had given good control in the past (Schwartz \& Siebert, 1987).

\section{MATERIALS AND METHODS}

Experimental layout: The experiment was carried out in a young vineyard (Vitis vinifera L. cv. Chenin blanc) at Simondium in the Western Cape. The vine cordons were approximately $750 \mathrm{~mm}$ above ground surface and trellised according to the Perold system.

Six chemical treatments (Table 1), together with an untreated control, were laid out in randomised blocks with five replications. Individual vines were selected for uniformity. Experimental vines in the same row were separated by four vines in the row.

An area of $300 \times 300 \mathrm{~mm}$ around the trunk of each experimental vine was cleared and leveled for the subsequent counting of snails. In order to ensure adequate numbers of snails and the uniform initial infestation of vines, snails were added or removed so that each experimental vine carried ten adult snails at the start of the experiment. Thereafter natural infestation was allowed.

Chemical treatments: Treatments were applied after bud burst (50 mm shoot length). All treatments, except metaldehyde paste, were applied with a knapsack sprayer. The entire vine, i.e. leaves and trunk, was sprayed until run-off occurred (approximately 0,51 of spray mixture per vine). For the application of metaldehyde paste, approximately $0,15 \mathrm{~g}$ of the product was squeezed from the container onto each cordon.

Experimental response: The efficacy of treatments was assessed weekly by counting the number of dead and live snails in the cleared space under each data vine as well as those found in the vine. At the same time all dead snails were removed. The percentage of dead snails was taken as a measure of response to treatment, i.e. the effectiveness of the

\footnotetext{
* Presented in part by the second author at the 1989 Conference of Biometric and Datametric Services, Dept. of Agric. Development, Pretoria.

Acknowledgement: The authors wish to thank Mr A. van Rooyen, Winter Rainfall Region, for computing services.
} 
chemical, and calculated from the cumulative snail counts for 30,44 and 70 days post-treatment. The cumulative number of dead snails was computed at 10-day intervals in order to determine the residual toxic effect.

Statistical analysis: Treatments were compared with respect to percentage kill by means of weighted least squares regression using the interaction of treatment, block, time, and treatment by time, as predictors. The observations from the control were omitted from the regression analysis because the inter-block variation was negligible in relation to that of the treatments. The calculations were carried out using a generalised linear-model computer program with a logic link function (Anon., 1980).

\section{RESULTS AND DISCUSSION}

Table 1 shows the total snail count and the percentage killed (mortality) for each treatment after 30, 44 and 70 days, obtained by combining replications (blocks). Mortality for the control was zero after 44 days in all but two of the blocks, and in all blocks it was less than $3,7 \%$ after 70 days (data not shown). The Table shows that the ranking of treatments with respect to observed mortality was remarkably consistent from one assessment time to the next. Thus metaldehyde paste and copper sulphate always gave the highest mortalities, alphamethrin and azinphos-methyl the lowest, and metaldehyde spray intermediate values.

The results of the statistical analysis are shown in Table 1. In contrast to a standard analysis of variance, the analysis here was complicated by the heterogeneity of variances among treatments, arising from the wide range of both per- centages and counts over treatments and replications. Furthermore, there was a considerable block effect and outlying observations for metaldehyde spray in block 5 (data not shown).

The heterogeneity of variance was taken into account by applying a logit transformation to the percentages, together with a weighting factor inversely proportional to the estimated variance (Snedecor \& Cochran, 1980). The weighting factor took care also of the outliers, because observations with small percentage counts received correspondingly small weights.

As shown in Table 1, the weighted estimates of percentage kill differed slightly from the unweighted ones, and notably so for metaldehyde spray, for which the weighting in block 5 (data not shown) was so small as to be nearly equivalent to regarding the percentage in that block as an outlier.

The necessity of the weighted logit analysis for this experiment was further demonstrated by carrying out an unweighted analysis (results not shown). It was found that the unweighted analysis failed to detect some of the significant differences resulting from the weighted analysis, e.g. the difference between metaldehyde spray and copper sulphate $5 \%$ at 30 days (Table 1 ).

With the exception of copper sulphate $5 \%$ and $10 \%$ at 30 days, and also metaldehyde spray and copper sulphate $5 \%$ at 44 days, all the treatments differed significantly $(\mathrm{P} \leq 0,05)$ from one another and from the control at each of the three assessment times. The standard errors were smallest for metaldehyde paste, azinphos-methyl and copper sulphate

TABLE 1

The effect of various chemical treatments on Helix aspersa at different times after application.

\begin{tabular}{|c|c|c|c|c|c|c|c|c|}
\hline TIME & & $\begin{array}{c}\text { alphamethrin } \\
@ \\
0,035 \% \text { a.i. }\end{array}$ & $\begin{array}{c}\text { azinphos- } \\
\text { methyl @ } \\
0,002 \% \text { a.i. }\end{array}$ & $\begin{array}{c}\text { metaldehyde } \\
\text { spray @ } \\
0,06 \% \text { a.i. }\end{array}$ & $\begin{array}{c}\text { copper } \\
\text { sulphate } \\
@ 5 \% \text { a.i. }\end{array}$ & $\begin{array}{c}\text { copper } \\
\text { sulphate } \\
@ 10 \% \text { a.i. }\end{array}$ & $\begin{array}{c}\text { metaldehyde } \\
\text { paste } \\
\text { @ 4\% a.i. }\end{array}$ & CONTROL \\
\hline 30 days & $\begin{array}{c}\mathrm{n} \\
\mathrm{d} \\
\mathrm{p} \\
\mathrm{p}^{*} \\
\text { s.e. }\left(\mathrm{p}^{*}\right)\end{array}$ & $\begin{array}{c}182 \\
49 \\
26,9 \\
28.6^{\mathrm{a}} \\
1.15\end{array}$ & $\begin{array}{c}418 \\
135 \\
32,3 \\
34.6^{\mathrm{b}} \\
0.52\end{array}$ & $\begin{array}{c}185 \\
90 \\
48,7 \\
52.4^{\mathrm{c}} \\
1.12\end{array}$ & $\begin{array}{c}165 \\
99 \\
60,0 \\
58.2^{d} \\
1.28\end{array}$ & $\begin{array}{c}276 \\
168 \\
60,9 \\
60.2^{d} \\
0.74\end{array}$ & $\begin{array}{c}498 \\
333 \\
66,9 \\
66.2^{\mathrm{e}} \\
0.44\end{array}$ & $\begin{array}{c}239 \\
1 \\
0,42 \\
- \\
-\end{array}$ \\
\hline 44 days & $\begin{array}{c}\mathrm{n} \\
\mathrm{d} \\
\mathrm{p} \\
\mathrm{p}^{*} \\
\text { s.e. }\left(\mathrm{p}^{*}\right)\end{array}$ & $\begin{array}{c}235 \\
49 \\
20,9 \\
21.9^{\mathrm{h}} \\
0.88\end{array}$ & $\begin{array}{l}512 \\
153 \\
29,9 \\
32 .{ }^{\mathrm{i}} \\
0.43\end{array}$ & $\begin{array}{c}206 \\
90 \\
43,7 \\
49.5^{j} \\
1.04\end{array}$ & $\begin{array}{l}194 \\
101 \\
52,1 \\
51.1^{\mathrm{j}} \\
1.09\end{array}$ & $\begin{array}{c}315 \\
181 \\
57,5 \\
56.7^{\mathrm{k}} \\
0.66\end{array}$ & $\begin{array}{l}588 \\
378 \\
64,3 \\
63.5^{\mathrm{i}} \\
0.38\end{array}$ & $\begin{array}{c}289 \\
2 \\
0,69 \\
- \\
-\end{array}$ \\
\hline 70 days & $\begin{array}{c}\mathrm{n} \\
\mathrm{d} \\
\mathrm{p} \\
\mathrm{p}^{*} \\
\text { s.e. }\left(\mathrm{p}^{*}\right)\end{array}$ & $\begin{array}{c}317 \\
50 \\
15,4 \\
17.2^{\mathrm{u}} \\
0.68\end{array}$ & $\begin{array}{c}589 \\
156 \\
26,5 \\
28.8^{v} \\
0.38\end{array}$ & $\begin{array}{c}249 \\
90 \\
36,1 \\
41.5^{w} \\
0.88\end{array}$ & $\begin{array}{c}225 \\
104 \\
46,2 \\
46.3^{3} \\
0.97\end{array}$ & $\begin{array}{c}378 \\
195 \\
51,6 \\
49.9^{\mathrm{y}} \\
0.55\end{array}$ & $\begin{array}{c}681 \\
403 \\
59,2 \\
58.0^{z} \\
0.33\end{array}$ & $\begin{array}{c}361 \\
6 \\
1,66 \\
- \\
-\end{array}$ \\
\hline
\end{tabular}

$\mathrm{n}=$ snail count, summed over replications.

$\mathrm{d}=$ cumulative number of dead snails.

$\mathrm{p}=$ observed $\%$ of snails dead.

$\mathrm{p}^{*}=$ weighted least squares estimate of $\%$ of snails dead;

s.e. $\left(\mathrm{p}^{*}\right)=$ standard error of this estimate;

$\mathrm{a}, \mathrm{b}, \ldots \mathrm{z}$ : estimates with the same letter in the same row do not differ beyond chance (at the $5 \%$ level of significance). 


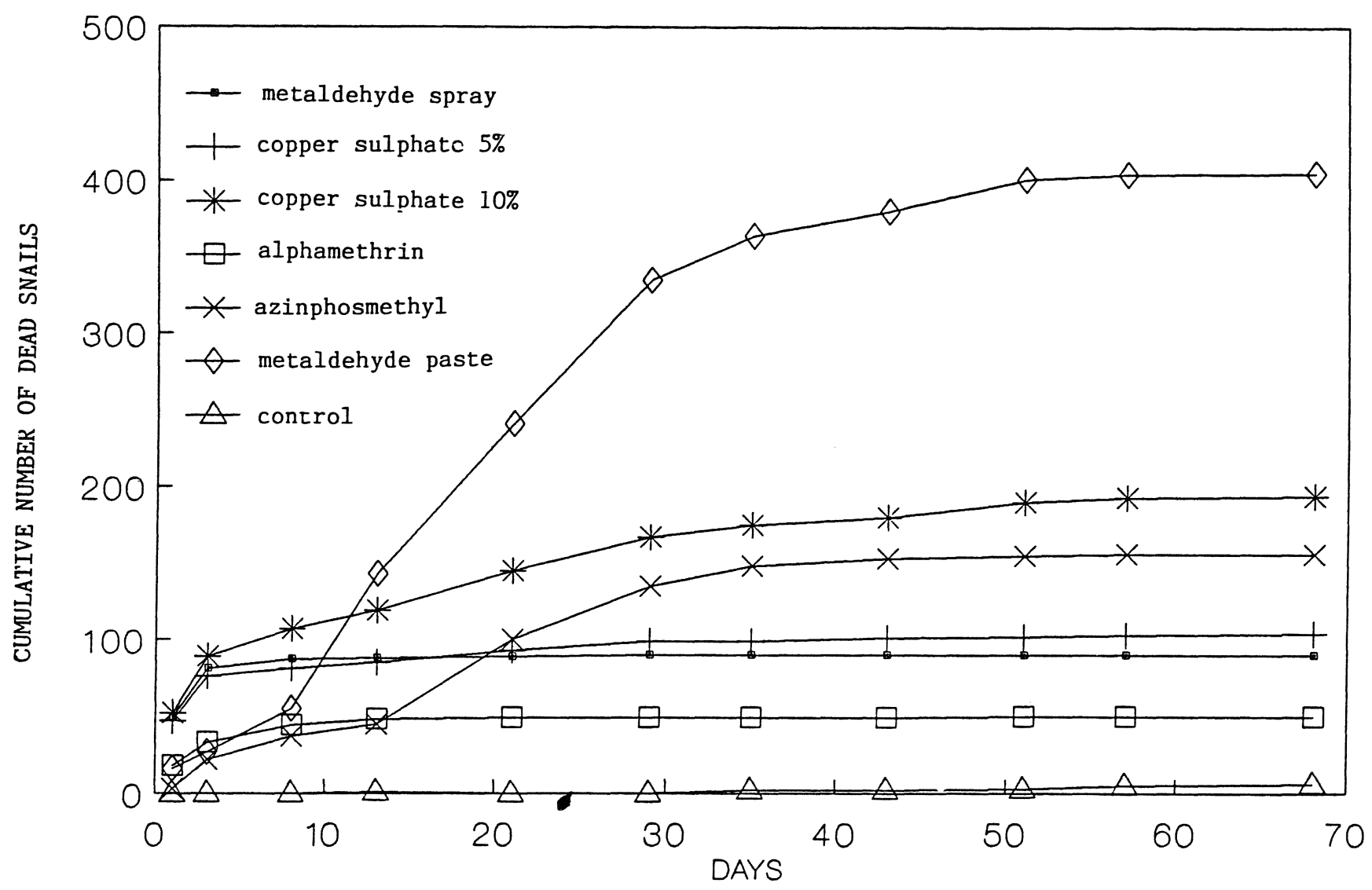

FIGURE 1

The comparison of treatments with respect to the duration of toxicity to Helix aspersa.

$10 \%$ because these treatments had the largest counts. With metaldehyde paste large numbers of snails were attracted by the bait component of the treatment, an ingredient that was lacking in the other treatments.

The rate of decline in mortality over time, averaged over all the treatments, was found to be about $1.8 \%$ per week, with a standard error of $0.25 \%$. The rate of decline did not, however, differ significantly between the two most toxic treatments, which were metaldehyde paste and copper sulphate $10 \%$.

With regard to residual toxic effect it should be noted that on the basis of the cumulative number of dead snails (Fig. 1), alphamethrin, metaldehyde spray and copper sulphate 5\% exerted their toxic effect only during the first 14 days of the experiment, whereas copper sulphate $10 \%$ and azinphosmethyl continued to kill snails for approximately 30 days and metaldehyde paste for approximately 52 days.

The highest kill rate was obtained with metaldehyde paste (66,2\% at 30 days). This was significantly better than the kill rates obtained with the copper sulphate treatments $(60,2 \%$ and $58,2 \%$ at 30 days). All other treatments gave substantially lower kill rates, and this held true also at 44 and 70 days.

The kill rates obtained with metaldehyde paste in the past (Schwartz \& Siebert, 1987) are comparable to those obtained in the present trial. Metaldehyde paste can be applied directly to the cordons or shoots of the vine, where it will adhere and exert a toxic effect.

With the copper sulphate applications, it was noted that snails on the vine immediately dropped to the ground, after being wetted with the spray, and died. Snails that attempted to crawl up the trunk of the vine soon after the application of the spray immediately dropped off. This indicated a strong repellent action. Winkler \& Chi according to Godan (1983) found that the substance has a certain repellent action at high concentrations. Unfortunately copper sulphate spray was found to be phytotoxic to the succulent shoots and leaves of the vine. In the light of these findings it is suggested that copper sulphate be tested in a follow-up trail as a spray applied to the trunk of the vine only, i.e. as a preventive trunk treatment.

With regard to the above treatments with the highest kill rates, it should be noted that percentage kill cannot be identified with effectiveness in controlling snails, without further assumptions or investigations regarding the effect of treatment applications on the total snail counts. For example, metaldehyde paste gave the highest percentage kill but also had the highest snail count; whereas alphamethrin, with a much smaller percentage kill but a smaller snail count, left fewer snails alive after 30 days (Table 1). In terms of surviving snails, therefore, metaldehyde paste was no better than alphamethrin under the circumstances of this trial. However, 
the expected comparative performance of the treatments in the presence of effectively equal or comparable snail counts can be inferred from the percentage mortalities and their standard errors obtained in the trial.

With regard to a criterion for the comparison of treatments the question arises whether the treatments should not have been compared in terms of percentage reduction in the number of live snails per vine relative to the control treatment. This would, however, require effectively equal counts among the treatments. Although some inequalities in the total counts appear to be inescapable under natural vineyard conditions, it may be possible in a future toxicity trial to eliminate major inequalities, e.g. by omitting treatments, such as metaldlehyde paste, with bait properties.

A more direct and perhaps more appropriate measure of snail control would be the percentage reduction of grape yield relative to the standard treatment and also relative to untreated vines. This method of comparison would have the advantage that it does not pre-suppose effectively equal snail counts, since it measures the resultant effect of attraction and toxicity.

\section{CONCLUSIONS}

The identification of significant differences of toxicity among chemicals was strongly dependent upon the right choice of statistical method. The use of a weighted least squares analysis was found to be necessary for this experi- ment because of major inequalities among snail counts (a natural phenomenon under vineyard conditions).

The highest percentage kill was obtained with metaldehyde applied as a paste onto each vine cordon. Copper sulphate sprays at $5 \%$ and $10 \%$ strength gave comparable kill rates but were phytotoxic to the vegetative parts of the vine. Such sprays should, therefore, be restricted to trunk treatments only, the effectiveness of which should be investigated in a future trial. Alphamenthrin, azinphos-methyl and metaldehyde gave unsatisfactory toxicity as spray applications, apart from the fact that the latter was also phytotoxic.

Instead of toxicity a more appropriate criterion of snail control would be the percentage reduction of grape yield, relative to the standard treatments and also relative to untreated vines.

\section{LITERATURE CITED}

ANONYMOUS, 1977. Pest control in young vines. Farmnote. Western Australia Department of Agriculture. No. 92/77.

ANONYMOUS, 1980. Genstat. Vol. 1, Lawes Agricultural Trust, Rothamsted Experiment Station, England.

GODAN, DORA, 1983. Pest slugs and snails. Springer-Verlag, Berlin.

LOUBSER, J.T., 1982. The control of snails in vineyards. Farming in South Africa. Viticultural and Oenological Series 97. VORI, Private Bag X5026, 7600 Stellenbosch, Republic of South Africa.

SNEDECOR, G.W. \& COCHRAN, W.G., 1980. Statistical Methods, 7th edition, lowa State University Press. p. 429

SCHWARTZ, A. \& SIEBERT, M.W., 1987. Field trials with toxic bait for the control of the brown garden snail (Helix aspersa Müller). S. Afr. J. Enol. Vitic. 8, 80-81. 